\title{
PI controller for DC motor speed realized with simulink and practical measurements
}

Mohammed A. Ibrahim, Ali N. Hamoodi, Bashar M. Salih

Department of Power Technical Engineering, Northern Technical University, Iraq

\begin{tabular}{|c|c|}
\hline Article Info & ABSTRACT \\
\hline Article history: & This article describes the methodology of speed control by understanding \\
\hline Received Mar 4, 2019 & $\begin{array}{l}\text { control method of DC motor, definitely, armature and field resistances with } \\
\text { additional to armature voltage control methods. The speed of DC motor is }\end{array}$ \\
\hline Revised Mar 21, 2019 & controlled PI controller as donor in this work. Using Matlab simulation and \\
\hline Accepted Nov 17, 2019 & $\begin{array}{l}\text { practical measurements, Terco DC motor speed control is achieved in this } \\
\text { work. The results that obtained from Matlab simulation circuit is appeared }\end{array}$ \\
\hline Keywords: & \\
\hline
\end{tabular}

Armature control

DC Motor

DC motor control

Field control

PI controller

This is an open access article under the CC BY-SA license.

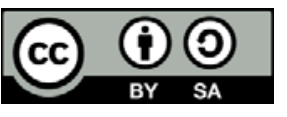

\section{Corresponding Author:}

Ali N. Hamoodi,

Department of Power Technical Engineering, Technical College of Engineering,

Northern Technical University, Mosul, Iraq.

Email: alihighvoltage@yahoo.com

\section{INTRODUCTION}

Background, control system is dealing with controlling a portion of an environment called (system plant) in order to emit desired products for society. The designing of an effective control system required prior information of plant. One of the engineering principles applications is DC motor [1]. For a long time, wide speed of DC motors in the industry control area due to many properties such as, high response performance high start torque, linear control.est. [2]. The speed of DC motor is donor by this relationship:

$$
N=\frac{V-I a R a}{k \emptyset}
$$

From a above equation, the speed is conditional related with the functional voltage $\mathrm{V}, \Phi$ and Ra. The article designates the Matlab/Simulink of DC motor speed control technique obviously armature control [3]. DC motors are divided into compound wound, series wound, shunt wound, and separately excited DC motors, the last type is the most used at universities [4]. The major methods to have controlled desired speedtorque characteristics of separately excited Dc motor; is to control the armature and field windings fed with variable sources [5]. The motor field winding is ligated to the supply for the speed control. The divers speed, credibility and high performance are three corer properties of an electrical drive system due to the austere control for Dc motor (low horse power) is low coast. By armature and field control, palatial range of variable speed below and above the maximum speed is achieved [6]. Separately exited DC motor is largely use in electrical drives. Many sorts DC motor in the commercial center [7]. PI controller represents $80 \%$ of controller applications because it is easy and fluent to understand [8]. DC motor is more adequate appearance 
used for manifold speed uses after a particular time for the sake of its high simplicity, accurate speed controller and controllable torque [9]. In this article, two problems are appeared. The first problem represented by software (Matlab / Simulink) program and the other problem represented by practical. The software problem is treatment by calculating the best parameters of PI controller and the practical problem is solved choosing the right torque that applied.

A method is proposed to design a PI controller for DC motor speed Matlab programming procedures are used to obtain the optimal response for DC motor with PI controller. The novel method for tuning PI controller is compared with Ziegler-Nichols first method. In order to select the optimum values of PI parameters, this required applying a novel method. This novel method can be dependent as easy to implement, simple concept and computationally efficient [10]. The proposed solution focus on designing the PI controller with DC motor and selecting the optimum parameters of PI controller in order to keep on the actual speed nearly from the reference speed. The motivation of using PI controller comes from the fact that this type of controller will make the error approach to zero (eliminate error).

\section{LITERATURE SURVEY}

Saleh Ebn Sharif and Anamika Bose [11]. These authors work on separately excited DC motor has parameters $(\mathrm{Ra}=1 \Omega, \mathrm{La}=0.05 \mathrm{H}, \mathrm{J}=0.01 \mathrm{kgm} 2 / \mathrm{s} 2, \mathrm{~B}=0.00003 \mathrm{Nms}, \mathrm{KT}=0.023 \mathrm{Nm} / \mathrm{A}, \mathrm{Kb}=0.023 \mathrm{Vs} / \mathrm{rad})$ they use many methods to study the DC motor speed response one these methods is PI controller. The transient response values that obtained from PI controller is peak over shoot time (20\%), max. time $(0.1 \mathrm{sec})$, rise time $(0.01 \mathrm{sec})$ and settling time $(1 \mathrm{sec})$.

Ujjwal Kumar, Devendra Dohare [12]. These authors work on separately excited DC motor. They apply three methods of control (Ziegler Nichols response, PI controller and PID controller) and compared between these types and the effect on DC motor speed response curve. The transient response values that obtained from PI controller is peak over shoot time $(19 \%)$, max. time $(1.19 \mathrm{sec})$, rise time $(6.01 \mathrm{sec})$ and settling time ( $34.1 \mathrm{sec})$.

\section{SEPARATELY EXCITED DC MOTOR}

\subsection{The equivalent circuit.}

This motor involves of independent double circuit, armature control and field control. The flux of excitation field is generated by DC motor field winding. The current is flowing into armature rotor across brushes and segments of commentator. The interaction between the segments and the field flux will produce the torque. Figure 1 represents the separately excited DC motor circuit.



Figure 1. DC motor separately excited circuit.

By exciting the DC separately motor with an ia and if the motor will produce a back E.M.F and providing a balance load torque at a particular speed. Because of armature winding is separated from field winding there for armature current does not depend on the field current. The armature current is higher than the field current [13].

\subsection{The mathematical model}

Kirchoff's law (KVL) is functional to the armature circuit as shown above it can be seen in Figure 1, the equations can be calculated as $[14,15]$ :

Int J Pow Elec \& Dri Syst Vol. 11, No. 1, Mar 2020 : 119-126 
Where,

$$
v_{a}=i_{a} R_{a}+L_{a} \frac{d i_{a}}{d t}+e_{g}
$$

$\mathrm{eg}=K$ vif $\omega$ leads to:

$$
v_{a}=i_{a} R_{a}+L_{a} \frac{d i_{a}}{d t}+K_{v} i_{f} \omega
$$

Using Laplace transform for (2) will give

$$
V_{a}(s)=I_{a}(s) R_{a}+L_{a} s I_{a}(s)+K_{v} I_{f} \omega(s)
$$

As a result:

$$
I_{a}(s)=\frac{V_{a}(s)-K_{v} I_{f} \omega(s)}{s L_{a}+R_{a}}
$$

And,

$$
T_{d}=J \frac{d \omega}{d t}+B \omega+T_{L}
$$

\section{SPEED CONTROL OF DC MOTOR}

PI Controller has a proportional and integral term in the forward path, this controller has the ability to make steady-state error equal zero. The block diagram of PI controller is shown in Figure 2 [16].

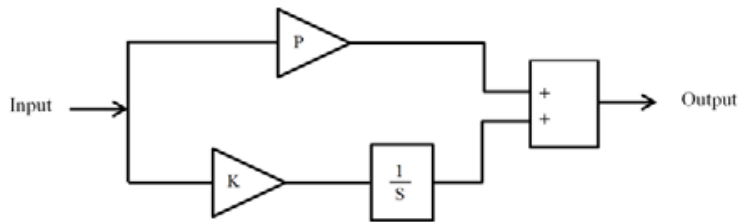

Figure 2. PI- representation

From block diagram a PI controller, one is inner current and second is speed loop. In the speed loop error represents the difference between desired speed and actual speed [17]. According to [18-20], there are four factors must be minimized by the control system:

- $\quad$ Rise time (tr): represents the time period from $10 \%$ to $90 \%$ of the desired value.

- Overshooting: represents the peak value of the response curve determined from the desired value.

- Settling (tss): represents the time required for actual output in order to reach and stay at percentage $(5 \%$ or $2 \%)$.

- $\quad$ Steady- state error: represents the difference between the actual output value and the desired required output

\section{THE CHARACTERISTICS OF PI CONTROLLER}

PI controller is using in the areas that have velocity of the system within large scale. The Kp part decreases the rise time, the $\mathrm{Ki}$ abolition the steady-state error only but it perhaps be performed to worse transient response. PI controller is mostly used in general applications of DC motors [21].

\subsection{Tuning PI controller}

The direct way is depending on the process model and the transfer function of the desired closed loop. The interests are that performance takes are incorporated squarely through the description of closed loop transfer function. The standard model is given in Figure 3. 


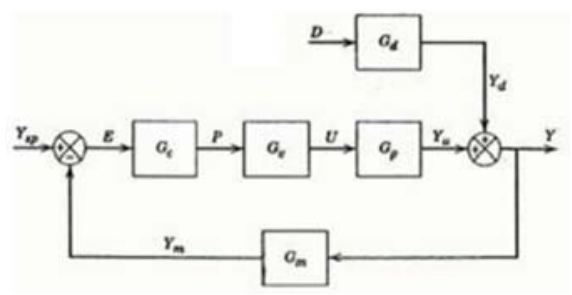

Figure 3. Standard closed-loop representation

The transfer function is depicted as:

$$
\frac{Y}{Y_{s p}}=\frac{G_{c} G_{v} G_{p}}{1+G_{c} G_{v} G_{p} G_{m}}
$$

Using Taylor series expansion [22]

$$
G_{c}=\frac{1}{\hat{G}} \frac{e^{\theta_{S}}}{\left(\tau_{c}+\theta\right) s}
$$

The time response analysis of a given system can be founded by converting the transfer function equation to the changeable in terms of time by regarding invers Laplace transformations. From the equation, multifarious time domain specification such as peak time, rise time, delay time and settling time can be calculated [23].

\section{DC MOTOR CONTROL BASED PI CONTROLLER}

PI controller consists of two terms (proportional and integral), the integral term gives this type of controller a characteristic property to eliminate the steady-state error and improving the speed response curve $[24,25]$. An adoption with large capabilities call for different PI gains than an adoption which works at a fixed speed [26]. Among six-decades ago, the application of PI controller with DC motors were capacious used than PID controllers [27].

The output of the PI controllers are acting as the modulation index of the converters but its output will give to the DC motor in order to obtain steady-state response for this motor speed and approached from reference value [28, 29]. Figure 4 represents an algorithm of DC motor speed control based PI controller. The proposed PI controller incorporated with DC motor in order to keep on actual speed nearly the reference speed

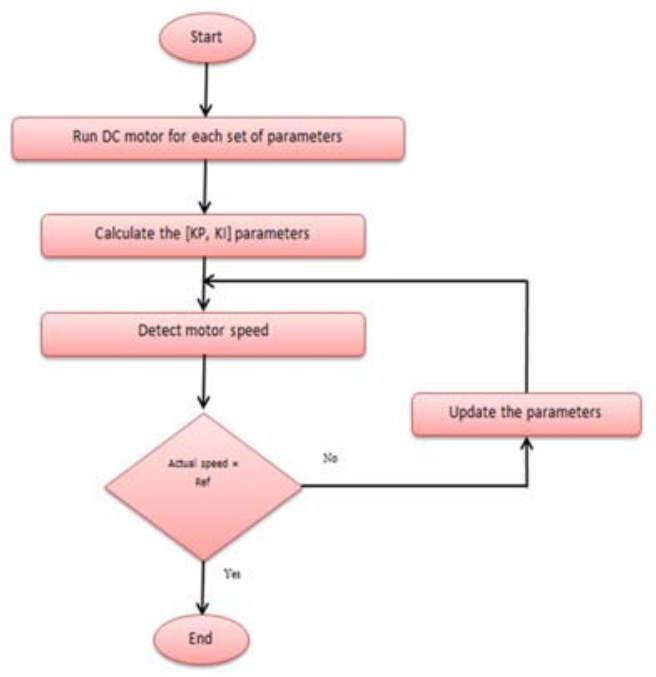

Figure 4. Algorithm process design flowchart 


\section{MATLAB REPRESENTATION}

Figure 5 represents the diagram of the Matlab simulation of PI controller of DC motor.

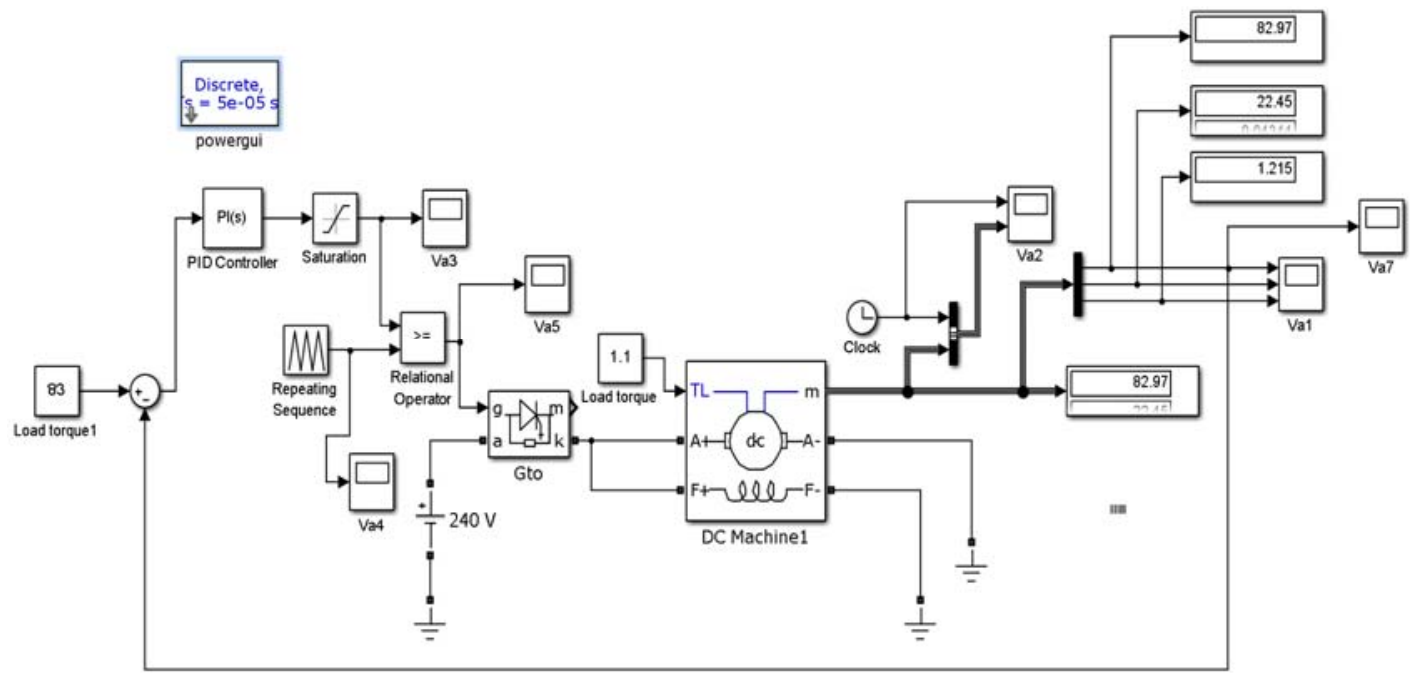

Figure 5. Modeling of DC motor control system

\subsection{Open Loop properties}

Terco DC motor specification is given in Table 1, the curve fitting is depicted in Figure 6.

Table 1. Description of terco DC motor

\begin{tabular}{cc}
\hline Parameters & Standards \\
\hline $\mathrm{Ra}$ & $0.25 \Omega$ \\
$\mathrm{La}$ & $60.81 \mathrm{mH}$ \\
$\mathrm{Jm}$ & $0.012 \mathrm{~kg} \cdot \mathrm{m}^{2}$ \\
$\mathrm{Bm}$ & $0.0204 \mathrm{~N} \cdot \mathrm{m} \cdot \mathrm{s} \cdot \mathrm{.rad}^{-1}$ \\
$\mathrm{~Kb}$ & $10 \mathrm{~V} \cdot \mathrm{s} \cdot \mathrm{rad}^{-1}$ \\
Rated speed & $1500 \mathrm{r} . \mathrm{p} . \mathrm{m}$ \\
\hline
\end{tabular}

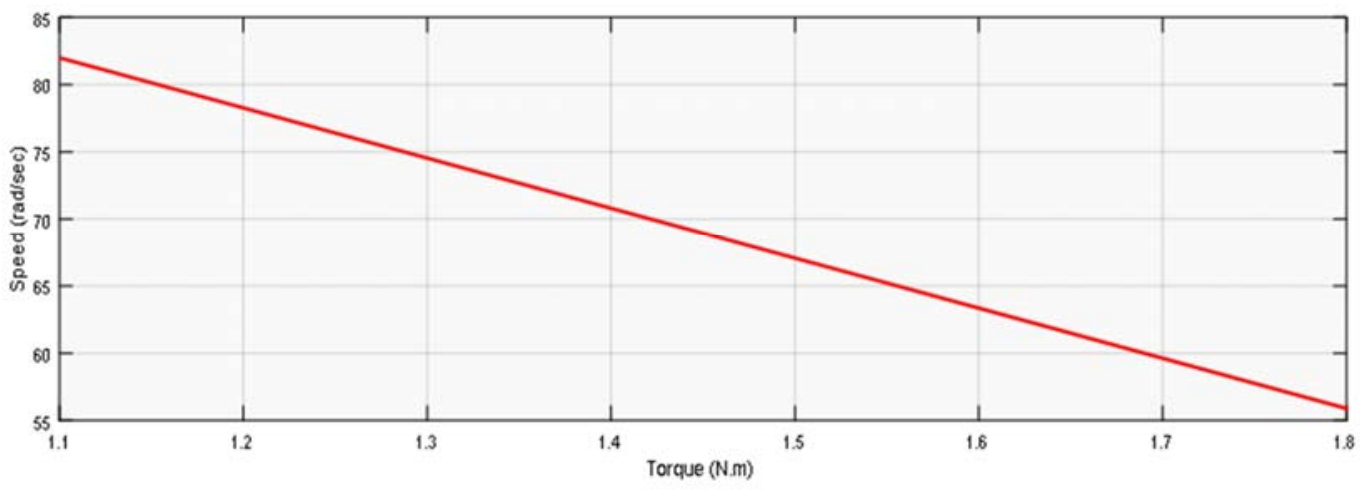

Figure 6. Open loop torque-speed curve.

\subsection{Closed loop characteristics}

PI factors enhancement the speed response curve. This upgrade can be seen as depicted in Figure 7. 


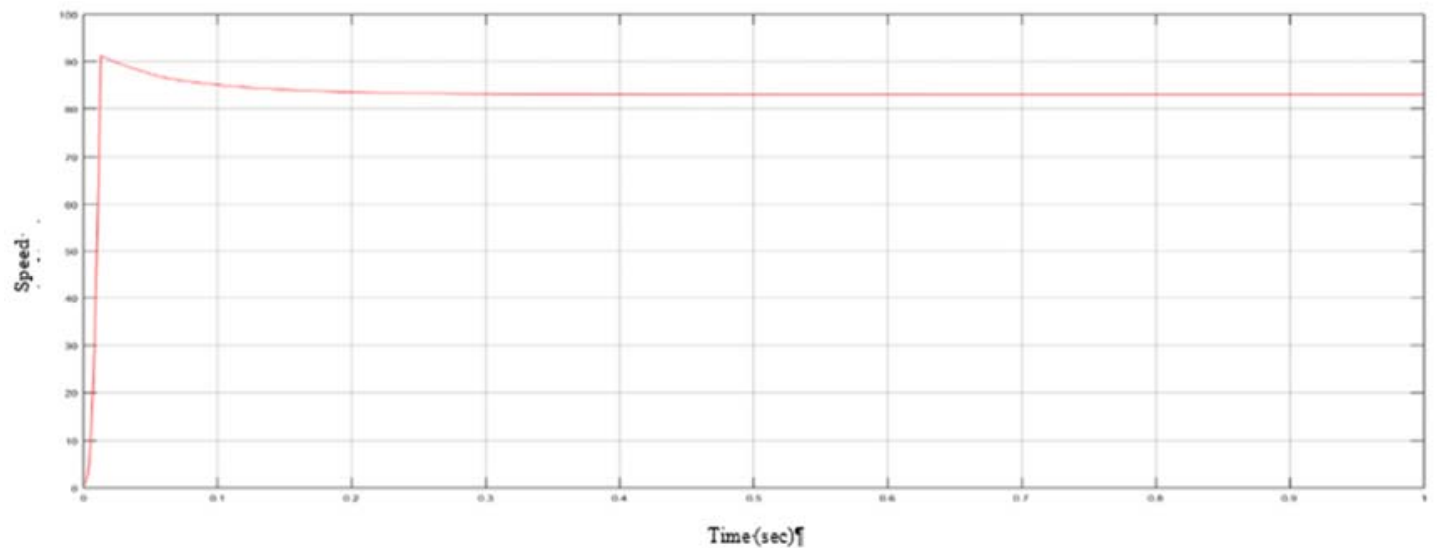

Figure 7. Improvement speed response with time $(\mathrm{Kp}=7.2, \mathrm{KI}=100)$

\subsection{Practical result}

The experimental torque - speed relationship is practically implemented with Terco DC motor as in Figure 8. The relationship between torque and speed for data given in previous is depicted in Figure 9.

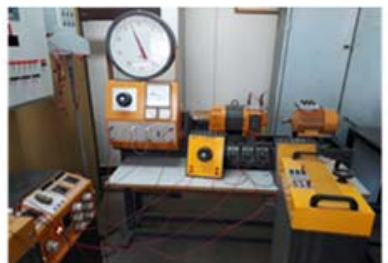

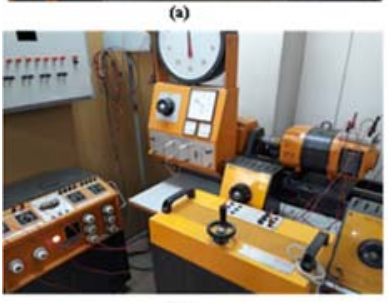

(c)
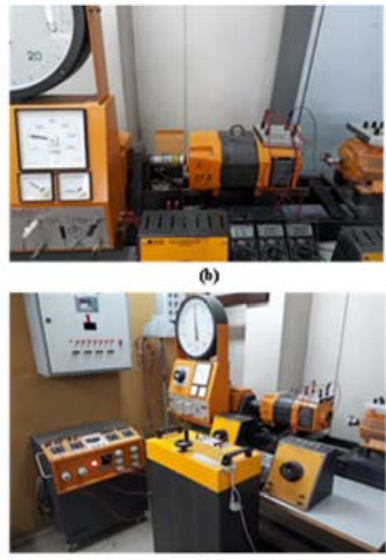

(d)

Figure $8(\mathrm{a}, \mathrm{b}, \mathrm{c}, \mathrm{d})$. Terco system connection.

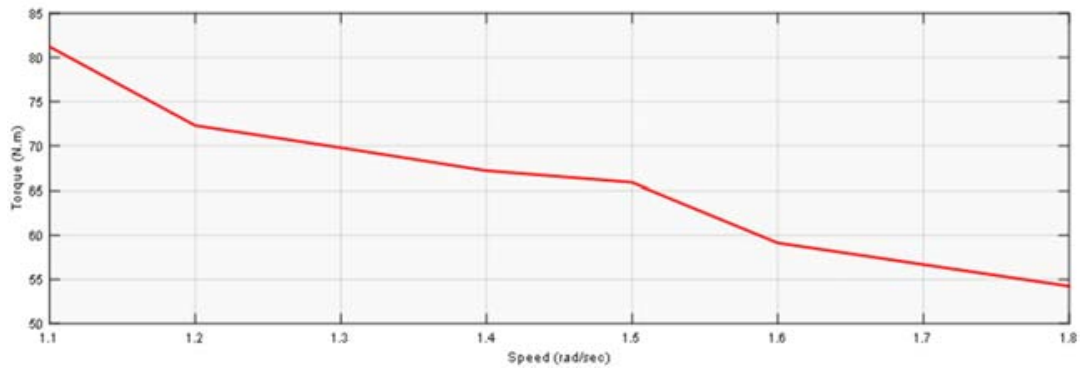

Figure 9. Practical torque-speed characteristics

The relationship between torque and speed is given in Figure 10. 


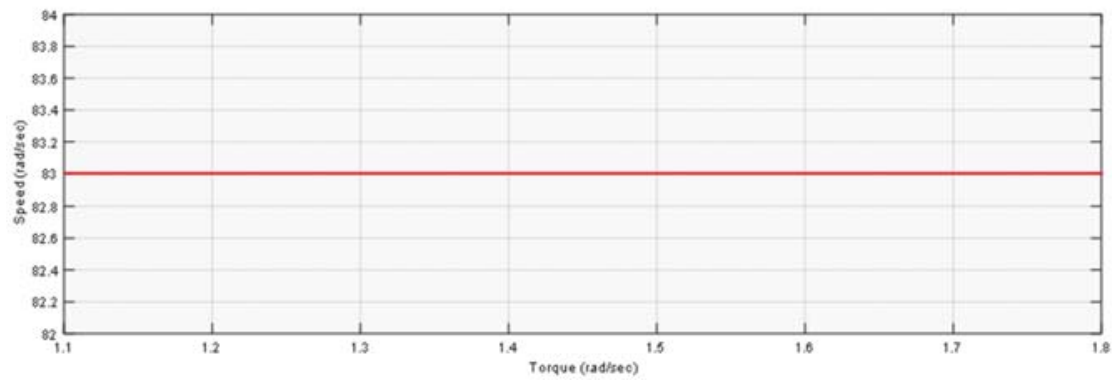

Figure 10. Practical torque - speed curve

\section{RESULTS AND DISCUSSION}

In this paper, PI controller used to find the suitable performance of DC motor speed control system. Figure (6) illustrates the speed responses of the separately excited DC motor drive with PI controller, the constant of PI controller $\mathrm{Kp}=7.2$ and $\mathrm{KI}=100$, give the best results for constant speed. The transient performance of this case can be shown in Table 2 .

Table 2. Transient performance results

\begin{tabular}{cccc}
\hline Rise time(s) & Max. time(s) & Overshoot (\%) & Settling time \\
\hline $0.01 \mathrm{sec}$ & $0.02 \mathrm{sec}$ & $9.638 \%$ & $0.2 \mathrm{sec}$ \\
\hline
\end{tabular}

\section{CONCLUSION}

From the results, the PI-controller solve the problems of large disturbance and noise during operation processer by eradicating enforced oscillations and steady state error subsequent in operation of PIcontroller.The simulation results are approximately similar to that obtained from the practical measurements. From the final table the speed values remain constant as respect to increase in the torque values.

\section{Nomenclatures:}

$\mathrm{V} \quad$ : source voltage (V).

$\mathrm{N} \quad$ : speed (rpm)

ia : current of the armature (A).

$\mathrm{Ra} \quad$ : resistance of the armature $(\Omega)$.

$\Phi \quad$ : flux (web).

$\mathrm{K} \quad$ : proportional fixed.

if $\quad$ : current of the field (A).

La : self inductance of the armature $(\mathrm{H})$.

eg : back EMF of the armature (V).

$\omega \quad$ : angular velocity ( $\mathrm{rad} / \mathrm{s})$.

Kv : voltage constant (V.s/rad).

Td : total torque (N.m).

$\mathrm{Jm} \quad$ : moment of inertia (kg.m2).

$\mathrm{Bm}$ : friction factor (N.m/rad/s).

\section{REFERENCES}

[1] Manoj Gogoi "Proportional-integral-derivative (PID) controller design for robust stability of arbitrary order plants with time-delay and additive uncertainty," Master thesis, Wichita State University, 2010

[2] R Omar A. Imran, Wisam Najm Al-Din Abed, Ali N. Jbarah "Speed control of universal motor," International Journal of Power Electronics and Drive Systems (IJPEDS), vol. 10, no. 1, pp. 41-47, Mar 2019.

[3] Aditya Pratap Singh, et al., "Speed Control of DC Motor using Pid Controller Based on Matlab," International Conference on Recent Trends in Applied Sciences with Engineering Applications, vol. 4, no. 6, 2013.

[4] Guoqiang Chen and Xianguang Shang, "Simulation used in education for a separately excited DC motor," World Transactions on Engineering and Technology Education, vol. 12, no.1, 2014.

[5] Ali Bekir Yildiz, "Electrical equivalent circuit based modeling and analysis of direct current motors," Electrical Power and Energy Systems 43, pp. 1043-1047, 2012. 
[6] Vitkramarajan Jambulingam, "Position control of Dc motor using pi controller," International Journal of Engineering Development and Research, vol. 4, no. 2, 2016.

[7] Ala Aldien Awouda, et al., "Speed control of DC motor using PI controller" IJCSMS (International Journal of Computer Science \& Management Studies), vol. 15, no. 06, 2015.

[8] M. V. Ramesh, J. Amarnath, S. Kamakshaiah and G. S. Rao "Speed control of brushless DC motor by using fuzzy logic PI controller," ARPN Journal of Engineering and Applied Sciences, vol. 6, no. 9, Sep 2011.

[9] Manjusha Patil, "Modelling and simulation of dc drive using PI and PID controller," International Journal of Innovative Research in Electronics, Electronics, Instrumentation, and Control Engineering, vol. 2, no. 12, 2014.

[10] Abidaoun H. shalla11, Rawaa A. Karim2, Osama Y. Al-Rawi 3 "A novel method for tuning PID controller," Diyala Journal of Engineering Sciences, vol. 06, no. 01, pp. 62-74, Mar 2013.

[11] Saleh Ebn Sharif1 and Anamika Bose2 "Performance comparison of PI and IP controller in speed control of DC motor," European Journal of Advances in Engineering and Technology, vol. 4(12), pp. 888-895, 2017.

[12] Ujjwal Kumar, Devendra Dohare, "Separately excited DC motor speed control of using various tuning conventional controllers," International Research Journal of Engineering and Technology (IRJET), vol. 02, no. 08, Nov 2015.

[13] Mohd Khairul Aklibin Ab Ghani, "Development of PID current control for DC motor using arduino" Master thesis, Universiti Tun Hussien Onn Malaysia, July, 2014.

[14] Md Akram Ahmad, Kamal Kishor, Pankaj Rai, "Speed control of a DC motor using controllers," Automation, Control and Intelligent Systems, acis.s.2014020601.11, ISSN: 2328-5591, Nov 20, 2014.

[15] Gafari A. Adepoju , Ismail A. Adeyemi, Oluwadolapo S. Oni, "Application of fuzzy logic to the speed control of DC motor," International Journal of Engineering Trends and Technology (IJETT), vol. 15, no. 5, Sep 2014.

[16] Ujjwal Kumar, Devendra Dohare, "separately excited dc motor speed control of using various tuning conventional controllers," International Research Journal of Engineering and Technology (IRJET), vol, 02, no. 08, Nov-2015,

[17] Pragya Jain, et al., "Comparative analysis of PI, PID and IP controller schemes for controlling speed of a DC MOTOR" International Journal of Electrical and Electronics Engineers, vol. 9, no. 01, Jan2 017

[18] Ahmed M. Ahmed, et al., "Brushless DC motor speed control using both PI controller and fuzzy PI controller," International Journal of Computer Applications, vol. 109 no. 10, Jan 2015.

[19] Tay, Teng-Tiow; Iven Mareels; John B. Moore, "High performance control," Birkhäuser, pp. 93, 1997.

[20] Ogata, Katsuhiko, "Discrete-time control systems," Prentice-Hall, ISBN 0-13-216102-8, pp. 344, 1987

[21] Mohd Azri Bin Abd Mutalib, "Speed control of DC motor using PI controller," Master thesis, Universiti Malaysia Pahang, May, 2008

[22] Masood Nazir, "Design of PLC based speed control of DC motor using PI controller," International Journal of Scientific and Technical Advancements, vol. 4, no. 1, pp. 5-8, 2018.

[23] D Vimalakeerthy, "Time response analysis of DC motor using armature control method and its performance improvement using PID controller," European Journal of Advances in Engineering and Technology, vol. 2(6), pp. 56-61, 2015.

[24] R. Nagarajan, et al., "Chopper fed speed control of DC motor using PI controller," Journal of Electrical and Electronics Engineering (IOSR-JEEE), vol. 11, no. 3, pp. 65-69, May 2016.

[25] Ujjwal Kumar, Devendre, "Separately excited DC motor speed control of using various tuning conventional controller," International Research Journal of Engineering and Technology, vol. 02, no. 08, Nov 2015.

[26] R. Nagarajan, et al., "Chopper Fed Speed Control of DC Motor Using PI Controller," IOSR Journal of Electrical and Electronics Engineering (IOSR-JEEE), vol. 11, no. 3, pp. 65-69, May 2016.

[27] V. M. Venkateswara Rao, "Performance analysis of speed control of DC motor using P, PI, PD and PID controllers," International Journal of Engineering Research \& Technology (IJERT), vol. 2, no. 5, May 2013

[28] R. Nagarajan, et al., "Implementation of chopper fed speed control of separately excited DC motor using PI controller," International Journal Of Engineering And Computer Science, vol. 6, no. 3, pp. 20631-20633, 2017.

[29] Aziz Ahmed, et al., "Comparative study of speed control of DC. motor using PI, IP, and fuzzy controller," International Journal of Advanced Research in Computer and Communication Engineering, vol. 2, no. 7, Jul 2013

Int J Pow Elec \& Dri Syst Vol. 11, No. 1, Mar 2020 : 119-126 